rev.relac.int.estrateg.segur.5(2):211-233,2010

\title{
LA SEGURIDAD NACIONAL COLOMBIANA EN VILO. ANÁLISIS MULTIDIMENSIONAL A LOS RETOS PROPUESTOS POR EL RÉGIMEN VENEZOLANO*
}

\author{
Alexander Montero** \\ Juan Ricardo Sánchez ${ }^{* * *}$ \\ Mary Liliana García**** \\ Liana Abril Pérez ${ }^{* * * *}$
}

\section{RESUMEN}

El presente artículo se presenta como la primera parte de los resultados de investigación sobre las amenazas a la seguridad nacional colombiana, identificando como fuente al régimen venezolano. De esta manera se plantea que el régimen venezolano, movido por el discurso bolivariano y escondiendo serias

Este trabajo es producto de investigación del proyecto EES-582 «Análisis de las amenazas externas a la seguridad nacional. La fuente venezolana», adscrito al grupo «Sociedad, Estrategia y Seguridad» de la Facultad de Relaciones Internacionales, Estrategia y Seguridad de la Universidad Militar Nueva Granada (UMNG).

** Politólogo, de la Universidad Nacional de Colombia. Magíster en Análisis de Problemas Políticos, Económicos e Internacionales contemporáneos. Doctorante en Estudios Políticos y Relaciones Internacionales. Experto en relaciones internacionales, seguridad y defensa. alexander.montero@gmail.com.

*** Economísta, de la Universidad San Buenaventura. Magíster en Seguridad y Defensa Nacional. Especialización en Seguridad y Defensa. Especialización en Estado Mayor. juanricardo.sanchez@yahoo.com

**** Politóloga, de la Pontificia Universidad Javeriana. Magíster en Inteligencia Estratégica y Prospectiva. Magíster en Seguridad y Defensa Nacional. liliana_garcia4@hotmail.com

${ }^{* * * * *}$ Profesional en Relaciones Internacionales y Estudios Políticos, joven investigadora. abrilperez84@hotmail.com. Se destaca la colaboración en este proyecto de cinco estudiantes investigadores. 
crisis socio-políticas y económicas, puede constituir una amenaza a la seguridad nacional colombiana y sentir interés en zonas estratégicas colombianas tales como La Guajira y Arauca.

Palabras clave: Venezuela, Colombia, Seguridad Nacional, Crisis Económica, Socialismo, Amenaza.

\section{ABSTRACT}

This article presents the first part of the results of an investigation on the threats to the Colombian national security, identifying as origin the Venezuelan regime. Thus, it is set forth that the Venezuelan regime, inspired by the Bolivariano speech and hiding serious social, political and economic crisis, can be a threat to the Colombian national security and experience interest in Colombian strategic zones such as Guajira and Arauca.

Key words: Venezuela, Colombia, National Security, Crisis, Socialism, Risk.

\section{INTRODUCCIÓN}

Este artículo busca analizar las posibilidades de una incursión armada por parte de Venezuela a Colombia, basado en el proyecto de Revolución Bolivariana, en el marco de la teoría realista en la cual prevalece el lenguaje del poder; lo anterior en la búsqueda por evidenciar cómo la lectura del sistema internacional define el accionar de los Estados, estableciendo su posición en el concierto internacional.

Para tal efecto, se propone un análisis estructurado en cinco partes; en primer lugar analizar a la República Bolivariana de Venezuela y a la República de Colombia (y sus orientaciones en seguridad) desde las vertientes ofensiva y defensiva, con lo cual se determinará el comportamiento de los mismos en el concierto internacional; posteriormente, se describirá el proyecto de Revolución Bolivariana y la configuración del sistema político venezolano que de este se deriva, con el ánimo de determinar por qué constituye una amenaza para Colombia. Luego, se evidenciará la forma en que la construcción de imaginarios colectivos $^{1}$ es un componente esencial en la estrategia de Seguridad Nacional de Venezuela, además de poner de manifiesto la importancia que se atribuye a la educación como elemento estratégico para la expansión de la Revolución

1 Acuñando el concepto de Néstor García Canclini, quien bajo el título de «Culturas híbridas: Estrategias para entrar y salir de la modernidad» explica el empleo que se da de los medios masivos de comunicación para construir nociones compartidas por colectividades a favor de proyectos como el predominio de la lógica del mercado, entre otras estrategias para generar identidad cultural desde la afinidad de los imaginarios. 
Bolivariana. A continuación se realizará una estructura y perspectiva económica venezolana como factor de riesgo a la seguridad nacional y, para finalizar, se propone al departamento de Arauca como posible escenario de una incursión armada debido a sus riquezas naturales.

\section{ANALISIS DESDE LA ÓPTICA DEL REALISMO DEFENSIVO Y OFENSIVO: El caso colombo-venezolano}

Dentro del marco de la teoría realista se explicará el comportamiento de Venezuela desde la óptica del realismo ofensivo, de Hans Morguenthau, cuya premisa básica indica que los Estados buscan el poder; asimismo Colombia será analizada desde el realismo defensivo, de Kenneth Waltz, quien afirma que los Estados están mas orientados hacia la búsqueda de la seguridad sobre la búsqueda de poder ${ }^{2}$.

A partir del 15 de diciembre de 1999 Venezuela, bajo el gobierno de Hugo Chávez, legitima su proyecto de Revolución Bolivariana a través de la reforma a la Constitución ${ }^{3}$, la cual incluye entre sus programas sociales misiones encaminadas al desarrollo de la educación (Robinson, Sucre, Ribas) y otras enfocadas a la prestación de salud en los lugares más apartados (Barrio Adentro); a pesar de ser creadas para favorecer aparentemente a la población venezolana también se benefician colombianos con cédulas venezolanas, pues son políticas implementados en zonas fronterizas.

A su vez, estas acciones por parte del gobierno venezolano pueden ser leídas como estrategia de guerra psicológica, creando entre la población aledaña a su frontera la conciencia colectiva, fundada en el agrado y reconocimiento al Estado proveedor y paternalista, resquebrajando el sentido nacional e influyendo en la toma de decisiones; es así como dentro del imaginario propuesto por el Estado paternalista acogerán de manera voluntaria la adopción de una nueva nacionalidad, si se presentara la oportunidad de elegir.

Es por ello que, a diferencia de lo planteado por Huntington con su premisa del «choque de las civilizaciones», las cuales están determinadas por las diferencias de religiones o creencias, la

2 PETROLLINI, D. Realismo Ofensivo y Realismo Defensivo: El debate Intrarrealista. Centro Argentino de Estudios Internacionales Programa Teoría de las Relaciones Internacionales. Búsqueda realizada el día 10 de junio. Desde <http://www.caei.com.ar/es/programas/teoria/29.pdf>

3 Reforma a la Constitución de la República de Venezuela a través de referendo. Por la cual se amplía a seis años del mandato presidencial, unifica las Fuerzas Armadas, crea un Parlamento unicameral e instituyó dos poderes más, el Electoral y el Ciudadano que se sumaron a los tres ya existentes (Ejecutivo, Legislativo y Judicial). Semana. Constitución venezolana impulsada por el presidente Hugo Chávez cumple 10 años. Búsqueda realizada el 21 de junio de 2010. Desde < http://www.eltiempo.com/mundo/latinoamerica/ARTICULO-WEB-PLANTILLA_NOTA_INTERIOR-798617.html> 
composición de una nueva unidad entre dos grupos sociales (ubicados en la zona fronteriza entre Colombia y Venezuela), identificados por las similitudes culturales y divididos por una nacionalidad, podría constituir el inicio de una nueva conquista, no precisamente alcanzada por la vía de las armas ni la violencia, sino determinada por el poder de suplir las necesidades básicas de la población penetrada. En este sentido Waltz afirma.

«Las fastidiosas cualidades de la inevitable desigualdad de los Estados no deben Ilevarnos a pasar por alto las virtudes. En una economía, en un gobierno o en el mundo en general, la desigualdad extrema está asociada a la inestabilidad. Para establecer una analogía doméstica: cuando el individualismo es extremo, cuando la sociedad es atomística y cuando están ausentes las organizaciones secundarias, los gobiernos tienden a caer en la anarquía o bien a tornarse altamente centralizados y despóticos» ${ }^{4}$.

En otras palabras, cuando existe desigualdad y olvido por parte del Estado se genera el espacio para que sus debilidades sean aprovechadas como ventajas por otros actores (Estados) quienes en la búsqueda de la maximización de su interés nacional usan su poder como medio para conseguir fines específicos, entrando en un juego de suma cero, donde las pérdidas de unos son las ganancias de los otros. A la luz del realismo ofensivo, el poder se convierte en un medio y no en el fin último. Siendo así, la estrategia social implementada por el Estado venezolano resulta un medio perfecto generador de caldo de cultivo para el inconformismo. De tal manera que encontrar aliados estratégicos facilita el ingreso sin resistencia a su territorio, alcanzado así recursos importantes para la consecución del expansionismo Bolivariano.

Por consiguiente, la explicación al proceder de aparente abandono del Estado colombiano está determinada por la implementación como bandera de lucha de la Política de Seguridad Democrática, la cual se enfocó en la recuperación y consolidación del control territorial y el fortalecimiento de las Fuerzas Militares, al cumplir con el objetivo elemental del Estado en el sistema internacional en la búsqueda de su seguridad, entendida en términos de conservación de su posición dentro del mismo ${ }^{5}$. Dentro del marco del realismo defensivo, incluiremos la variable de probabilidad alta de conflicto, determinada por Stephen Brooks, por la cual el accionar del Estado se encamina exclusivamente en la protección de su seguridad, dejando de lado otros intereses y centrando su sobrevivencia en la obtención de este objetivo. Por ello, es importante destacar que:

4 WALTZ. K. N. (1988). Teoría de la Política Internacional. Grupo Editorial Latinoamericano, Colección estudios internacionales. Buenos Aires, Argentina. Pág. 195.

5 PETROLLINI, Darío Damián. Realismo Ofensivo y Realismo Defensivo: El debate Intrarrealista. Centro Argentino de Estudios Internacionales - Programa Teoría de las Relaciones Internacionales. Búsqueda realizada el día 10 de junio. Desde < http://www.caei.com.ar/es/programas/teoria/29.pdf> 
En su perspectiva, la Fuerza Militar es el mayor recurso para garantizar la seguridad. La Fuerza Militar es una herramienta efectiva para la implementación de políticas definidas en las negociaciones diplomáticas. La Fuerza Militar se usa para dominar a otros ${ }^{6}$.

Por lo tanto, el Estado centra sus esfuerzos para proveer a su población de seguridad a través del fortalecimiento de sus Fuerzas Militares, sustentada bajo la premisa de la variable de probabilidad alta de conflicto, garantizando el statu quo y, por tanto, permitiendo a futuro al Estado enfocarse en otros temas como el social, el cual brindaría bienestar a la población.

Sin embargo, no se debe obviar la estrategia utilizada por el gobierno de Hugo Chávez en el ámbito social, la cual se ha venido implementando desde 1999, sin dejar de lado dentro de su proyecto el desarrollo de una economía productiva encaminada a la distribución de la riqueza, pues esto se podría llegar a constituir en el talón de Aquiles de la Política de Seguridad Democrática y, lo que es más importante, a pesar de invertir varios de sus recursos económicos en la llamada carrera armamentista y manejar un discurso intimidante, el presidente Chávez de manera paralela y de una manera formidable otorga la ley del garrote para el Estado colombiano, pero zanahoria para el pueblo colombiano afligido por el abandono de su gobierno; es por ello que el discurso social podría tener mayor peso sin necesidad de disparar una sola arma, decantando en la obtención de recursos naturales agrícolas y mineros, necesarios para la implantación del proyecto bolivariano en el resto de Latinoamérica.

\section{2. ¿QUÉ ES LA REVOLUCIÓN BOLIVARIANA Y POR QUÉ ES UNA AMENAZA PARA COLOMBIA?}

En la actualidad Venezuela asiste a una reestructuración nacional que transversaliza y modifica todos los ámbitos de la sociedad. El Gobierno del Presidente Hugo Chávez ha introducido reformas a las concepciones doctrinales que rigen la actuación estatal en materia política, económica, social y militar y promueve bajo el proyecto de Revolución Bolivariana nuevos mecanismos y procesos sistemáticos para la consecución de los intereses nacionales en materia de seguridad.

En efecto, Venezuela posee una visión integral y estratégica del conjunto de ideas, objetivos e instrumentos que estructuran su proyecto revolucionario, su aparato de defensa y seguridad, así como su accionar a nivel nacional, regional y global ${ }^{7}$.

ADENEY, Bernard. (1988). Just War, Political Realism, and Faith, New Jersey: The Scarecrow Press, p. 146. SÁNCHEZ, Rubén. (2005). Seguridades en construcción en América Latina, El círculo de Colombia: Brasil, Ecuador, Panamá, Perú y Venezuela. Centro de Estudios Políticos e Internacionales -CEPI-. Pág. 192. 
La justificación del proyecto que rige actualmente la política del Estado y la estrategia nacional venezolana está circunscrita al contexto de globalización y apertura de mercados. Dichos fenómenos, en principio económicos, se han caracterizado por la incapacidad para producir los mismos efectos para todos los actores que conforman el Sistema Internacional; si bien existen ventajas de la mundialización de la economía, estas recaen principalmente sobre los dueños del capital y las grandes industrias, configuradas como agencias multinacionales y empresas transnacionales, las cuales han alcanzado un óptimo nivel de inserción en la dinámica de productividad e innovación que exige la Globalización; por su parte, quienes se han quedado rezagados en el proceso de adaptación al cambio, se han visto afectados por la pérdida de oportunidades y la incapacidad para acceder a la cadena productiva y la consecuente reproducción de utilidad.

En efecto, quienes carecen de niveles adecuados de inversión en investigación y desarrollo tecnológico, entre otros factores de competitividad, han visto en forma más lenta, o quizás aún no han percibido ni accedido a los resultados positivos de la dinámica internacional a la cual se asiste en la actualidad.

Por tal motivo, en países como Venezuela, donde la economía está en desarrollo y donde la inminencia de las necesidades urgentes impide atender las realmente importantes, se ha emprendido la búsqueda de alternativas a la globalización como modelo de desarrollo; y en su reemplazo establece, como prioridad del Estado, la concentración de la atención en la búsqueda de solución de las demandas internas percibidas como insatisfechas y proyecta la reestructuración de la economía global en lugar de emprender un proceso de inserción.

Se promueve, entonces, un discurso fundado en modelos de desarrollo en los cuales el Estado debe ser el actor central de la dinamización económica de la sociedad, en oposición a los fundamentos del modelo de apertura, desregulación, liberalización del mercado y supranacionalidad. En otras palabras, se sobrepone la preeminencia del Estado-nación en un contexto donde su dominio tiende a verse cuestionado, debido a la transnacionalización de los problemas ${ }^{8}$ y al desdibujamiento de las fronteras.

De esta manera, el proyecto que sostiene la actividad estatal venezolana es consecuencia de la dinámica internacional y obedece al rechazo generado hacia la misma. Al respecto, resulta pertinente explicar la realidad interna que acompañó la definición de dicha postura

8 Al respecto, la Organización de las Naciones Unidas dictaminó que los problemas (tipificados como delitos) de índole transnacional, que amenazan al Sistema Internacional y ponen en entredicho la efectividad del control de los Estados, son la delincuencia organizada, el tráfico ilícito de drogas y armas, el contrabando, la trata organizada de personas, el terrorismo y el blanqueo (o lavado) del producto de delitos graves. (Art. 1, Declaración de las Naciones Unidas sobre el delito y la seguridad pública). 
«alterglobalizadora» ${ }^{9}$ en el país. En 1989 el Gobierno de Venezuela, en cabeza de Carlos Andrés Pérez, adoptó el Plan denominado «el Gran viraje», mediante el cual se instituyó el cambio de modelo asumiendo políticas de corte neoliberal ${ }^{10}$. Sin embargo, el país carecía de un sistema político efectivo, en tanto la ausencia de una democracia en las esferas económica, política y social restringía las garantías de participación y representación de la sociedad y por tanto impedía la generalización de condiciones de igualdad y equidad en todos los niveles de la nación.

En este contexto se gestó el inconformismo hacia el modelo de desarrollo planteado ${ }^{11}$ y se allanó el camino para la llegada al poder del Presidente Hugo Chávez en el año 1999, quien bajo el título de «Revolución Bolivariana» instauró un proyecto político reformista caracterizado por la búsqueda de un «nuevo modelo» para el país, en busca del establecimiento de una democracia participativa para una sociedad más justa y equitativa ${ }^{12}$.

Dicho proyecto se enmarca en la planeación de dos fases para su desarrollo, proyectadas a dos décadas, contemplando diez años para la transición del país al nuevo modelo y otros diez para la realización y el afianzamiento del mismo ${ }^{13}$. Dentro de la primera fase, de adecuación al cambio, se instauran mecanismos de transformación económicos, sociales, políticos, territoriales e internacionales, en aras de proyectar el Estado en cada una de estas esferas y sentar las bases para la ejecución de la Revolución.

9 El surgimiento de percepciones negativas en torno a las consecuencias de la globalización dio paso a la conformación de movimientos internacionales de resistencia antiglobalización, altermundistas o alterglobalización; este último término se acuñó debido al fenómeno según el cual dichos movimientos, a pesar de estar en contra de la globalización, se apoyan en el uso de las nuevas tecnologías, especialmente en el área de la comunicación, para superar las barreras espacio-temporales y por esta vía coordinar sus actividades. De este modo, no se postulan como movimientos en contra de la Globalización, sino como manifestaciones que proclaman una forma diferente de expandir el fenómeno mundializador; es decir, una manera alterna de globalización.

10 SÁNCHEZ, Rubén. Op.Cit. Pág. 200.

11 Inconformismo originado en la esfera del poder militar, donde se dio paso al surgimiento de dos tendencias: una inspirada en los postulados de seguridad-defensa y desarrollo (propias de la Doctrina de Seguridad Nacional basada en el modelo norteamericano) y otra que propendía por sintetizar en un solo proyecto las ideas nacionalistas, marxistas y populistas. En esta última se enmarca la aparición de la Revolución Bolivariana, pues dio lugar a la creación de logias secretas (como las denomina Domingo Irwin G.) dentro de las que se encuentra el MRB-200, conformado por un grupo de militares con ideales revolucionarios dentro de los cuales se encontraba el actual mandatario Hugo Chávez. (Sacado de: Domingo Irwin G. Una visión histórica de conjunto sobre las relaciones políticas entre los civiles y militares venezolanos en el siglo XX. Center for Hemispheric Defense Studies. REDES, 2001. Citado en: SÁNCHEZ, Rubén. Op.Cit. pág. 201).

12 SÁNCHEZ, Rubén. Op.Cit. Pág. 201.

13 Rubén Sánchez expone con detalle este asunto al explicar la forma en que las Líneas Generales del Plan de Desarrollo Económico y Social de la Nación 2001-2007, de la República Bolivariana de Venezuela, estipulan una década de Plata (entre el año 2001 y el año 2010) para la transición; y una década de oro (20102020) para la realización del proyecto. (Pág. 201). 
El cambio que dio inicio a la transición hacia la revolución fue la reforma a la Constitución y las leyes de la República, otorgando con esto un marco legal que establece las reglas de juego con las cuales se ampara la realización del proyecto en los campos de poder político, jurídico y económico de la Nación. Así, estando regido por la Constitución de 1999, el Presidente Chávez emprende el tránsito hacia la modificación del Estado, en un proceso fundado en la definición de objetivos e intereses nacionales basados en la búsqueda de la defensa costera y marítima, de las fronteras, la expansión del control ejercido sobre el territorio nacional, la defensa de los precios y mercados del petróleo ${ }^{14}$ y el posicionamiento regional e internacional del país, aspectos concebidos como los lineamientos bajo los cuales se diseñan las políticas de defensa y seguridad de Venezuela.

Partiendo de esta definición de los objetivos e intereses nacionales de Venezuela, se pasa ahora a identificar la forma en que dicho proyecto se configura como una amenaza hacia Colombia.

La Revolución Bolivariana denota una tendencia a lo internacional, puesta en evidencia tras la búsqueda de mecanismos de posicionamiento en la región que Venezuela considera como zona natural de influencia. Para dar cumplimiento a este objetivo se ha acudido al establecimiento de alianzas estratégicas con países que le proveen injerencia y elementos de poder, tales como Cuba, Irán, China y Rusia, los cuales cuentan con peso político, económico y militar en el sistema internacional ${ }^{15}$ y comparten además las líneas de pensamiento que rigen la Revolución Bolivariana, referidas al ejercicio de un contrapeso a Estados Unidos, a fin de dar paso a una reconfiguración con la cual otros bloques puedan acceder al poder global y restar la influencia estadounidense en los dictámenes internacionales.

En consecuencia, el Presidente Chávez concibe como amenaza para su país la participación de Estados Unidos en América Latina, pues le resta posibilidad de injerencia y posicionamiento en la misma como potencia regional. Lo anterior configura un problema para Colombia, en la medida en que instrumentos como la ayuda económica y militar otorgada por Estados Unidos en la lucha contra el narcotráfico y el terrorismo, en el marco del Plan Colombia, el Plan Patriota y más reciente, el acuerdo Suplementario para la Cooperación y la Asistencia Técnica y Seguridad ${ }^{16}$, es percibida

14 Íbidem. Pág. 199.

15 SÁNCHEZ, Rubén. Pág. 219

16 Este acuerdo de cooperación en defensa entre Estados Unidos y Colombia, afianza la estrecha relación estratégica entre los dos países en tanto que, como lo señala la Embajada de EEUU en Venezuela (en su página oficial) armoniza y actualiza los acuerdos bilaterales, las prácticas y los convenios vigentes sobre asuntos de seguridad y continúa asegurando la debida protección y estatus del personal estadounidense. Adicionalmente, indica que los compromisos bilaterales entre EE.UU. y Colombia en la esfera de la seguridad están regidos por condiciones establecidas en diversos acuerdos bilaterales, como el Acuerdo para la Asistencia de Defensa Mutua de 1952, el Acuerdo General para la Asistencia Económica, Técnica y Afines de 1962 y convenios posteriores de 1974, 2000 y 2004. 
como un instrumento estratégico norteamericano que se interpone como obstáculo a la difusión de su proyecto bolivariano en Colombia y, por tanto, se perfila como una amenaza contra su nación, contra la cual se deben emprender acciones inminentes.

Tal puede ser entendida como la justificación de la campaña de desprestigio y deslegitimación de la ayuda que recibe Colombia, emprendida por parte de agentes legales e ilegales que a través de medios de comunicación masivos y diplomáticos buscan copar la opinión pública nacional e internacional con mensajes que cuestionan la legalidad con que actúa el Estado colombiano, poniendo en entredicho su credibilidad y motivando por esta vía el cierre de los lazos políticos y económicos tendidos con Colombia. Por su parte, el Presidente de Venezuela opera bajo los supuestos según los cuales, en la medida en que se reduzca la provisión de recursos, se genere presión social interna y el poder político quede en manos de sectores opositores a la tendencia conservadora, se ampliará la posibilidad de que Colombia ceda en su posición y adquiera compromisos con el País vecino y, por esta vía, se adhiera a la Revolución Bolivariana, situación en la cual se ampliaría la esfera de influencia venezolana y se eliminaría el eje de poder sobre el cual opera Estados Unidos en la región, produciendo un desbalance que le otorga la ventaja estratégica al proyecto bolivariano para su consolidación ${ }^{17}$.

Con respecto a dicha zona de influencia, se debe precisar el sector del hemisferio americano que resulta comprometido; es decir, las subregiones sobre las cuales Venezuela busca extender su dominio. Para tal efecto, resulta pertinente describir la forma en que por su ubicación geográfica Venezuela tiene vínculos con tres zonas económicas y culturales, a saber: Andina, la subregión amazónica (la brasilera, en particular) y el Caribe $^{18}$.

En consecuencia, la ubicación geográfica del país favorece la proyección venezolana en el ámbito internacional. No obstante, los vínculos que mantiene con cada una de las áreas señaladas se diferencian entre sí, y en el caso andino, especialmente con Colombia, se han caracterizado por la existencia de intereses opuestos en materia de la definición limítrofe de los respectivos territorios. En tal sentido, se ha dado lugar a problemas fronterizos ${ }^{19}$ y es con base en estos que ha surgido la necesidad de entablar lazos y escenarios de política exterior ${ }^{20}$.

17 Aún así, Venezuela ha propendido por el mantenimiento de lazos de cercanía con Estados Unidos en tanto es su principal comprador de petróleo, y este es a su vez el recurso que sostiene la economía nacional

${ }^{18}$ MEDINA, Medófilo (2003). Venezuela: confrontación social y polarización política. Bogotá, Ediciones Aurora.

19 Problemas ocasionados por la demarcación de las líneas fronterizas, estipuladas en el acuerdo bilateral de 1941, el cual carece de legitimidad por parte del Gobierno venezolano, que reclama soberanía en el área de la Guajira, el Zulia y el Táchira; lugares en disputa debido a la presencia de importantes bases y recursos fundamentales para el acceso a poder y posicionamiento geopolítico y geoeconómico.

20 PETRASH, Vilma E. (2001) Venezuela's National security policy Ander the Chavez regime: the impact of changed perceptions and practices on Venezuelan regional dynamics. Center of Hemispheric Defense Studies, REDES. Citado en: SÁNCHEZ, Rubén. Pág. 193). 
Vemos así la manera en que Colombia, en su condición de país andino, forma parte del escenario estratégico sobre el cual se planea y ejecuta la defensa de los intereses venezolanos. De igual forma, como país vecino cuenta con las condiciones para ser permeado por el proyecto de Revolución mediante el cual se busca materializar dicha defensa. Factores que sumados convergen en la asimilación de Venezuela como país de origen de amenazas a la estabilidad y seguridad colombianas.

De otro lado, el escenario se complejiza al tener en cuenta que la existencia de un conflicto de carácter no internacional en Colombia ha dado lugar a la configuración de un contexto desprovisto de fortalezas para la defensa de los intereses nacionales en el ámbito de la política exterior, pues los esfuerzos se concentran en la atención prioritaria de las problemáticas de orden interno, dejando de lado la inminencia de la influencia que desde afuera se ejerce sobre la Nación y las debilidades que esto trae consigo.

En este sentido, la búsqueda de expansión del dominio de Venezuela para posesionarse como potencia regional en contrapeso a la hegemonía norteamericana, sumado al diferendo en materia limítrofe, ocasionado por el deseo proveniente del país vecino de acceder al dominio del área en disputa y por esta vía reducir el territorio colombiano con las implicaciones geopolíticas y geoestratégicas que, por ejemplo, la pérdida de la Guajira o los Llanos Orientales traería consigo, y la situación de violencia en Colombia, han configurado una realidad en la que la Revolución Bolivariana y las acciones que de esta se desprenden llevan a postular la necesidad de atender la realidad fronteriza como una prioridad del Estado colombiano en aras de salvaguardar los intereses nacionales, empezando por la soberanía y la integridad territorial, así como la seguridad en general.

\section{MISIÓN EDUCATIVA Y CONSTRUCCIÓN DE IMAGINARIOS: COMPONENTES FUNDAMENTALES DE LA ESTRATEGIA DE SEGURIDAD BOLIVARIANA}

Ahora bien, pasemos a analizar uno de los componentes esenciales en la Revolución Bolivariana, referido a la construcción de esquemas de gestión general y coordinada entre los órganos que componen el Estado y la redefinición de las relaciones civiles - militares en el marco de la acción de construcción de imaginarios como pilar sobre el cual se soporta la ejecución de dichos proyectos.

En cuanto a la ejecución del proyecto de expansión del poderío venezolano cabe señalar que este conlleva el fortalecimiento de las capacidades en materia militar como soporte de las acciones del Estado. Dicho supuesto configura la necesidad de contar con un estamento armado capaz de validar el discurso que proclama a Venezuela como país en condiciones de extender su dominio. En este sentido, una de las tareas derivadas de la Revolución Bolivariana ha sido la definición de nuevas competencias para el estamento militar, las cuales se han traducido en la 
politización y el empoderamiento para incidir, de forma vinculante, en la definición de los mandatos nacionales ${ }^{21}$. Tal medida ha dado lugar al debilitamiento del carácter subordinado del poder militar al civil, propio de las democracias (su ausencia ha conducido a la factibilidad de gestación y desarrollo de un régimen descrito como oclocracia y liderazgo personalizado ${ }^{22}$ ), con la consecuente incapacidad del poder civil para ejercer control efectivo en la definición y planeación estratégica en materia de seguridad.

De este modo, las reformas implementadas al sistema que rige la nación han posicionado a las Fuerzas Armadas como actores fundamentales, deliberantes y, por tanto, determinantes en la construcción estratégica del Estado. De otra parte, dentro del proyecto de Revolución Bolivariana se dio inicio a la modernización de los equipos técnicos y armados, realizando compras a gran escala ${ }^{23}$ que se interpretan como el desarrollo de una carrera armamentista en el país. Aspectos que sumados son el soporte sobre el cual se llega a percibir en Venezuela una amenaza a la estabilidad en materia de seguridad colombiana e incluso regional ${ }^{24}$.

Lo anterior constituye un riesgo en la medida en que, al carecer de un poder de constricción sobre los titulares de la fuerza, se tiende a privilegiar la resolución de los conflictos por medio del uso de la vía armada ${ }^{25}$. Tal circunstancia da lugar a la descripción de Venezuela como un Estado de soberanía excluyente, con una democracia restringida, en el cual el gobierno interno de la población no cuenta con mecanismos para dar cumplimiento al propósito fundacional de garantizar la sumisión de los asociados al imperio de la ley.

Además, la defensa y la seguridad se plantean de manera egoísta sumiendo al Estado en el llamado «Dilema de Seguridad», definido por Armando Borrero en su artículo Defensa y seguridad

21 SÁNCHEZ, Rubén. Pág. 216.

22 Sistema que se opone a la esencia de la democracia representativa, fundada en la separación de poderes y en un sistema de pesos y contrapesos entre los diversos órganos del Estado, la cual es caracterizada por su complementariedad con el modelo liberal, en forma contraria a la democracia directa y popular (como lo explica Norberto Bobbio, en su Diccionario de política. Pág. 1392).

${ }^{23}$ Dentro de las que se incluyen: 100.000 fusiles AK-47 y 40 helicópteros a Rusia, además de la compra propuesta al Gobierno de España para el suministro de 10 aviones de transporte medio C-295 dos aviones de vigilancia marítima tipo $\mathrm{CN}-235$ Persuadir y once navíos (frente a la cual se impusieron restricciones norteamericanas), bajo el argumento de fortalecer la lucha contra las drogas ilícitas en la costa Atlántica.

24 Tal percepción es expresada por el exministro de Defensa colombiano, Jorge Alberto Uribe, en los siguientes términos: «es un hecho innegable que el reequipamiento militar venezolano profundiza el desbalance militar en la región andina (...). En estos momentos no existe una clara justificación para la adquisición de ciertos tipos de armas de alcance estratégico en una región que ha liderado la limitación en los gastos militares». (En: Gobierno colombiano cuestiona carrera armamentista venezolana. Disponible en: http:// es.wikinews.org/wiki/Gobierno_colombiano_cuestiona_carrera_armamentista_venezolana.)

${ }^{25}$ BORRERO, Armando. Defensa y seguridad nacional: elementos para una política democrática. En: Revista Análisis Político. No. 42. IEPRI. Pág. 28. 
nacional: elementos para una política democrática, como aquella situación en la cual los Estados fortalecen su poder armamentista, se militarizan para aumentar su propia seguridad y al hacerlo aumentan la inseguridad de los otros Estados, los cuales, a su vez, recurren al armamentismo, dando paso a un contexto en el cual todos los Estados se ven envueltos en condiciones de menor seguridad $^{26}$.

Es así como el proyecto que establece las bases para el desarrollo económico de la nación venezolana posiciona a las Fuerzas Militares como un actor fundamental para la preservación de los intereses vitales de la nación (que como ha sido mencionado, se definen en torno a la defensa costera y marítima; el control e integridad del territorio, en especial las fronteras; y la defensa de los precios y mercados del petróleo), extendiendo además el papel funcional que deben cumplir las Fuerzas Armadas en el Estado y enfocándose en labores de corte humanitario y de labor social que favorezcan su posicionamiento en la estructura organizacional.

Además, se establece que dichas Fuerzas Armadas no pueden operar de manera aislada, en tanto debe existir un vínculo entre la provisión de seguridad y el desarrollo integral dirigido a proveer condiciones óptimas de calidad de vida a la población ${ }^{27}$. De esta manera se sugiere la corresponsabilidad entre la población y las Fuerzas Armadas en temas de seguridad, dejando en manos del Estado la integración del territorio y el ejercicio de un control efectivo sobre el mismo mediante planes de asistencia social, en materia educativa, en salud, alimentación, desarrollo endógeno y misiones para la institucionalización de ciudadanía activa, entre otros ${ }^{28}$.

En este contexto, la búsqueda de garantías a las demandas sociales insatisfechas postula la prestación de un óptimo servicio de asistencia social; sin embargo, desde una óptica estratégica, dicho provisionamiento de servicios esenciales está soportado en la necesidad de extender y legitimar el proyecto de Gobierno. Es decir, se otorgan beneficios a la población, pero orientados a la búsqueda de adhesión por parte de los receptores hacia la estrategia. Aunque cabe señalar que discursivamente, y como parte de la estrategia, dichas acciones son presentadas como comportamientos movidos por el altruismo o el cumplimiento de los deberes y obligaciones del Estado hacia sus electores ${ }^{29}$. No obstante, el trasfondo está dado por el fenómeno de aprobación, validación y legitimación mencionado.

26 BORRERO, Armando. Pág. 29.

27 La ley orgánica de seguridad del año 2002 establece que los intereses del Gobierno se centran en incrementar las condiciones de vida de los venezolanos, brindándoles la posibilidad de participar en forma más activa en la definición de su proyecto de nación, cuya seguridad exige la corresponsabilidad entre el Estado y la sociedad civil.

28 Íbidem. Pág. 217.

29 Dentro de los objetivos misionales de los frentes que actúan a nombre de la Revolución, como lo es el Frente Francisco Miranda, se encuentran: crear conciencia revolucionaria en el pueblo a través de la cultura, la formación política, la recreación sana y la participación social en virtud del concepto de defensa 
De este modo, frases como la que sigue:

«iLa única forma de poner fin con la pobreza es dándole poder al pobre. Conocimiento y conciencia son el principal poder!»

\section{Presidente Hugo Chávez}

Denotan el manejo discursivo señalado; sin embargo, se debe entender qué hay detrás de la eliminación del analfabetismo en Venezuela. Según lo expuesto, la implementación de planes educativos, bajo el nombre de la Misión Robinson, en el territorio del país vecino, obedece a la estrategia o proyecto de Revolución Bolivariana, lo cual se hace evidente al entender la relación que existe entre dicha misión educativa y las Fuerzas Armadas del país, que son las encargadas de garantizar, mediante acciones civiles-militares, la ejecución de dichos programas, obteniendo con esto la generalización de una percepción favorable al trabajo mancomunado entre el Gobierno y las Fuerzas Armadas, así como hacia la estrategia que orienta su labor, evidenciando que en último término el impacto generado es la legitimación del proyecto gubernamental, expresada en la siguiente frase:

«La idea es que todos en Venezuela sepan cómo leer y escribir. Entonces, cuando Chávez haga algo, pueden buscar en la Constitución y ver si está autorizado, si es legalı».

Ahora bien, se debe tener en cuenta que el impacto es reforzado mediante la elaboración de contenidos educativos por medio de los cuales se fortalece la cultura cívica de la población, se le vincula con los asuntos públicos y se le instruye en materias relacionadas con la Revolución. La Constitución y la información que se difunde en los medios de comunicación son lecturas obligatorias que confirman la proyección estratégica de la educación como herramienta para consolidar un imaginario de apoyo social a la identidad nacional construida desde el Gobierno y de rechazo a los postulados que la contradigan.

De este modo, se pone de manifiesto el trasfondo político que configura el traspaso del discurso bolivariano, empleando la educación más que como un proyecto de ayuda social, como un medio de difusión de su revolución, obteniendo apoyo de la gente en tanto se ha promovido

integral de la Nación y la formación de «Deber Social» que compromete a los beneficiarios a manera de retribución. Lo cual constituye un riesgo para Colombia, en la medida en que las misiones son ejercidas en territorio fronterizo y, por lo tanto, fungen como medio de coerción a la población colombiana sujeta a recibir los beneficios de atención social y a la consecuente «concientización» de la necesidad de apoyar la Revolución.

30 SARAH, Wagner. Venezuela: territorio libre de analfabetismo. Artículo digital disponible en: <http:// www.voltairenet.org/article124921.html> 
una conciencia colectiva que considera como motivo de este proyecto la necesidad de proveer educación a la sociedad, para erradicar la pobreza e insertar en la dinámica productiva a los receptores del servicio, mas no por la expansión que esto representa del poder venezolano en materia ya no económica y social sino político-militar.

Queda claro entonces que la educación no se ve como un deber del Estado sino como una herramienta al servicio de la estrategia y el proyecto nacional. De igual forma, en términos de política exterior, el Gobierno venezolano ha difundido que en los países latinoamericanos la educación no se ve como derecho sino como privilegio, argumento bajo el cual han expandido su esfera de acción e implantado su proyecto Robinson en distintos países de la región, buscando con esto partir de un desprestigio gubernamental, logrando persuadir a la población y acrecentar su ámbito de aplicación y ejercicio del poder. La estrategia consiste entonces en deslegitimar al Estado, copar espacios estratégicos como la opinión pública nacional, en especial la fronteriza, y difundir el modelo venezolano como el adecuado.

Al respecto cabe citar, a manera de ejemplo, una realidad visibilizada mediante un acontecimiento reciente. En diciembre de 2009 Venezuela solicitó que la Unión Internacional de Telecomunicaciones (organismo de Naciones Unidas) diera apertura a una investigación oficial contra la presunta violación de los acuerdos internacionales por parte de Colombia tras la «invasión» del espectro radioeléctrico debido a que la emisora del Ejército alcanzaba su difusión en la zona de frontera común ${ }^{31}$. Sin embargo, el País denunciante justificó su amplitud del espectro y la transmisión que alcanza en territorio colombiano, tras afirmar que en respuesta al hecho reseñado debía afianzar su influencia mediante el fortalecimiento de las emisoras venezolanas en Colombia, dando potencia a su cobertura y a sus mensajes.

Lo anterior, en departamentos como Arauca se complejiza, por cuanto los canales de acceso a formación de opinión pública se restringen a los venezolanos debido a que las emisoras nacionales colombianas no alcanzan a tener cobertura en la zona, con lo cual se deja a la población araucana en manos de los mensajes transmitidos por el Presidente Chávez, a diario, en su programación discursiva de oposición al modelo estatal colombiano y, a la vez, a los lectores se les deja bajo la construcción de imaginarios desde la perspectiva de los grupos armados ilegales, con predominio del Ejército de Liberación Nacional el cual, a través de sus medios impresos, su presencia física, los vínculos familiares que guardan sus integrantes con los habitantes de la zona, sumado a la coacción y coerción que sobre ellos ejerce, mantiene una ventaja estratégica de dominio ilegal sobre el territorio, la mente y el corazón de los habitantes de la zona, ${ }^{32}$ lo cual supone un doble riesgo por

31 Venezuela denuncia a Colombia ante la ONU por «invasión» del espectro radioeléctrico. Diario El Universal. Búsqueda realizada el 26 de mayo de 2010. Desde: <http://www.eluniversal.com/2009/12/22/ pol_ava_venezuela-denuncia-a_22A3223255.shtml >.

32 No solo obtiene la cooperación de la población mediante la violencia, sino a través de su presencia como agente mediador en la resolución de los conflictos como consecuencia del abandono estatal a que ha 
cuanto deja el espacio propicio para la construcción de los imaginarios colectivos de rechazo a la institucionalidad democrática colombiana y abre una ventana de oportunidad a la consecuente influencia e invasión venezolana en el marco de la Revolución Bolivariana.

Lo que ha dejado ver la república bolivariana es un continuo interés por su presencia en las cercanías a la frontera que colinda con la Guajira y también la que lo hace con Arauca. Y por esto es que Colombia, una vez percibida la amenaza, requiere encargarse de la situación en estas dos plazas con un corte estratégico de prevención más que de reacción ante un eventual ataque. Ahora bien, la hipótesis afirma que en el caso de que se dé la invasión, esta será por Arauca y no por la Guajira, como muchas veces se ha afirmando; a continuación se argumentará el porqué.

\section{ESTRUCTURA Y PERSPECTIVA ECONÓMICA VENEZOLANA COMO FACTOR DE RIESGO A LA SEGURIDAD NACIONAL}

El comportamiento macroeconómico de Venezuela ha sido errático durante 30 años. Las riquezas naturales, fundamentalmente la dependencia mono-productora del petróleo, han hecho que la estructura económica de Venezuela sea frágil, lo cual, aunado a una burocracia corrupta, decisiones erróneas y el privilegio al gran capital extranjero, produjeron pérdidas significativas en la producción venezolana y lograron una de las inflaciones más altas del mundo.

\subsection{La Economía Venezolana como proceso. La transición al siglo XXI}

Es posible afirmar que al finalizar la primera década del siglo XXI, Venezuela se encuentra en una crisis económica, disfrazada por un pequeño repunte entre el año 2003 y el año 2009, y por medidas controversiales como profundas devaluaciones o manejos estéticos a la inflación. Para analizar esta situación, es pertinente separar tres momentos en el recorrido de la historia económica venezolana. El primero, los años comprendidos en las dos últimas décadas del siglo XX, en los cuales la economía venezolana vivió rezagos del auge petrolero de los 70, que incluyeron la nacionalización de la industria petrolera venezolana y el fortalecimiento de la OPEP, y que cayó

estado sometido el Departamento, cuyo referente de presencia institucional legal se traduce en el Ejército, frente al cual existen reservas por cuanto su llegada a la zona se percibe como respuesta a las demandas de seguridad interpuestas por las compañías extranjeras de explotación de petróleo, y no por la defensa de los intereses de desarrollo social y crecimiento económico de los habitantes de la región. Situación que ha dejado a los integrantes del ELN con la ganancia del apoyo material e inmaterial de la población y deja en desventaja al Ejército Nacional, al ser concebido como ente que en lugar de proteger a la sociedad araucana, ataca a la guerrilla que los ha defendido tradicionalmente y guarda entre sus miembros a sus hijos, hermanos, amigos y demás personas cercanas por afinidad ya no solo ideológica sino por vínculo de afecto personal. 
luego en una franca decadencia. El segundo, corresponde al primer periodo del gobierno del presidente Chávez, caracterizado por una profunda crisis económica reflejada en el PIB y en la inflación anual. El tercero, casi coincidente con el segundo periodo del presidente Chávez, se caracteriza por un repunte económico debido a los precios récord petroleros y a algunas medidas de ajuste estructural tomadas por el gobierno central que, sin embargo, parecen llevar nuevamente a Venezuela a la continuación de su crisis.

\subsubsection{Años 80 y 90, un gigante con pies de barro. Inicio de la crisis económica venezolana}

En la primera mitad de los setenta, y como influencia de la OPEP, se dio el gran boom petrolero mundial, lo cual facilitó una expansión del ingreso fiscal en Venezuela ${ }^{33}$. Por un lado, los ingresos producto de las importantes exportaciones petroleras se ahorraron en el fondo de inversión de Venezuela. No obstante, la mayor parte fue gastada generando así una expansión económica y monetaria que dio origen nuevamente a presiones inflacionarias ${ }^{34}$. Esta situación se convierte en una constante en el manejo estructural económico venezolano, por lo cual se puede afirmar que, desde la óptica neo-institucionalista, la crisis venezolana tiene un fondo más profundo. Por otro lado, entre 1974 y 1975 se decreta por parte del gobierno la nacionalización de la industria petrolera y del hierro, pasando a ser potestad exclusiva del Estado la explotación del petróleo en todas sus fases realizada por la empresa de petróleo de Venezuela (PDVSA) ${ }^{35}$.

En este escenario, la evolución del PIB venezolano desde finales de la década de los setenta se caracterizó por un comportamiento irregular, con alta volatilidad que reflejaba la pérdida de dinamismo económico y agotamiento del modelo rentista petróleo sobre el que se ha sostenido la económica venezolana ${ }^{36}$.

El fin del boom del petróleo y su impacto en la economía venezolana se evidenció en los años 80. La economía venezolana se contrajo drásticamente, aumentando la deuda pública (ya de por sí amplia desde el manejo económico dado en los 70) y la cuenta corriente de la balanza de pagos fue negativa, lo que determinó un descenso significativo en las reservas monetarias internacionales ${ }^{37}$. Por otra parte, la tasa de inflación superó, en promedio anual, el $25 \%$, siendo una de las más altas de América Latina.

33 Espinaza Ramón. Auge y colapso de PDVSA a los treinta años de la nacionalización. En: Revista venezolana de Economía y Ciencias Sociales. Vol 12 No 001. 2006. Pág 154.

34 Ibid.

35 Ibid. Pág. 155.

${ }^{36}$ Kornblith Miriam. Crisis y transformación del sistema político venezolano: nuevas y viejas reglas de juego. Publicado en Latin American Studies Association. Búsqueda realizada el 26 de mayo de 2010. Desde: $<\underline{\text { http://lasa.international.pitt.edu/LASA97/kornblith.pdf }>\text {. }}$

${ }^{37}$ Merchel Dorotea. La industrialización de Venezuela. En: Revista Economía. Facultad de Ciencias Económicas y Sociales. Instituto de Investigaciones Económicas y Sociales. No 10. Pág. 78. 
Los años 90 iniciaron con buenas expectativas para Venezuela debido a la primera Guerra del Golfo y al incremento de los precios del petróleo derivado de ella. No obstante, el desmesurado gasto público, la corrupción imperante y, sobre todo, la quiebra bancaria durante el gobierno del presidente Caldera, hicieron que la crisis económica apareciera nuevamente ${ }^{38}$.

\subsubsection{Primer periodo del Presidente Chávez. Crisis económica = moderación económica y política}

Finalizando los 90, los recortes a la producción petrolera, ordenados por la OPEP, ayudaron a incrementar los precios internacionales, de manera sostenida en los dos primeros años del siglo $\mathrm{XXI}$, y produjeron un mejoramiento de la balanza de pagos, un aumento de las reservas internacionales y una disminución de la inflación a un $20 \%$. Por esto, en el año 2000 , fruto de nuevas políticas monetarias y fiscales que apuntaban a la expansión del gasto social y la disminución de la inflación, hubo un crecimiento del PIB venezolano del $4 \%$ y una disminución de la inflación al $13.4 \%{ }^{39}$. Las variables macroeconómicas parecían tomar un buen camino.

Es importante notar que, según González ${ }^{40}$, el comportamiento beligerante del presidente Chávez no fue notorio en este periodo. Los principales esfuerzos estaban dados en consolidar una recuperación económica. Sin embargo, luego de esta relativa mejoría, y sobre todo a partir del año 2004, la recuperación económica venezolana se acompaña de una seria beligerancia y un discurso bolivariano del cual se desprenden amenazas para la seguridad nacional colombiana.

\subsubsection{Segundo periodo del Presidente Chávez. Prosperidad económica inestable = belige- rancia política regional}

Entre el año 2004 y el año 2007, el crecimiento económico venezolano fue sostenido, logrando incluso cifras récord de dos dígitos. Esta situación se acompañó de un incremento significativo de las reservas internacionales de Venezuela y de una ajuste «estético» de la inflación al eliminarse tres ceros en las denominaciones monetarias ${ }^{41}$. La mejoría macroeconómica, sin embargo, no fue producto de un ajuste estructural o de un re-direccionamiento macroeconómico, como sería lo esperado al evaluar el comportamiento venezolano de las dos décadas anteriores, sino

38 Ibid.

39 Ibid.

${ }^{40}$ González María Fernanda. Los Discursos de Hugo Chávez. ¿Tan solo palabras?. Búsqueda realizada el 4 de junio de 2010. Desde: < http://www.eltiempo.com/domingoadomingo_eltiempo/los-discursos-de-hugochavez-tan-solo-palabras 4876166-1>.

41 Wexell Luciano. Economía Venezolana (1899 - 2008): La lucha por el petróleo y la emancipación. Fundación Editorial El Perro y la Rana. Caracas 2009. Pág 28. 
por los altísimos precios internacionales que logró el petróleo luego de los ataques del 11 de septiembre de 2001 y de las campañas militares iniciadas por Estados Unidos en Afganistán e Irak ${ }^{42}$.

Sin embargo, este comportamiento especulativo de la economía venezolana empezó a entrar en franca decadencia con el descenso de los precios internacionales durante el año 2008, afectando gravemente el gasto público y la balanza de pagos en el país. La inflación se registró en un $30.9 \%$, la más alta en la región por segunda vez consecutiva ${ }^{43}$.

La crisis económica apareció nuevamente en el panorama venezolano. La industria nacional, ya debilitada por su estructura mono-exportadora, enfrentó retos profundos desde 2008. Por tal motivo, en el año 2010 se tomó la decisión de la devaluación del bolívar y el establecimiento de dos tipos de cambio con miras a facilitar la competitividad sectorial de Venezuela. Se estableció un tipo de cambio para sectores prioritarios como salud y alimentación a 2,6 bolívares/dólar y otro llamado «dólar petrolero» de 4,3 bolívares/dólar para otros rubros como el automotriz, comercio y telecomunicaciones ${ }^{44}$.

Este segundo periodo del presidente Chávez se caracteriza por una marcada beligerancia, profundizada ahora por una evidente inestabilidad política y económica. Sus posturas han caminado hacia la confrontación y la insistencia con un modelo de integración bolivariano que, en últimas, ayude al sistema productivo venezolano, sirviendo de complemento a su débil, especulativa y mono-productora economía.

\section{AMENAZAS HACIA LA SEGURIDAD NACIONAL COLOMBIANA. A LA DEFENSA DE LOS INTERESES ESTRATÉGICOS}

Los escenarios de inestabilidad política y económica comúnmente llevan a roces regionales. El escenario andino parece no ser la excepción. Una valoración de los intereses venezolanos puede sugerir que ante una gran crisis económica interna, y buscando una nueva unidad nacional,

42 ARENAS, Nelly. Estado y transnacionales petroleras: de la «»»apertura»»» a la «»»re-nacionalización»») de los hidrocarburos en Venezuela. En: Revista Venezolana de Análisis de Coyuntura [en línea] 2008, vol. XIV no. 001. Búsqueda realizada el 12 de mayo de 2010. Desde: < http://redalyc.uaemex.mx/redalyc/src/inicio/ ArtPdfRed.jsp?iCve=36414106. ISSN 1315-3617>.

43 Indicadores macroeconómicos. Venezuela 1999-2007. En: Revista Venezolana de Análisis de Coyuntura [en línea] 2008, vol. XIV no. 001. Búsqueda realizada el 12 de mayo de 2010. Desde: <http:// redalyc.uaemex.mx/redalyc/src/inicio/ArtPdfRed.jsp?iCve=36414115. $>$.

${ }^{44}$ García Sofía. Venezuela: una y otra vez el sistema dual de tipos de cambio. En: Centro de estudios Latinoamericanos. CESLA. Búsqueda realizada el 3 de junio de 2010. Desde: < http://www.cesla.com/analisis/ archivos/doc01_10.pdf $>$. 
se encarrilen las amenazas hacia sus vecinos. En ese sentido resulta particularmente importante la concepción de una potencial amenaza en dos sectores estratégicos colombianos, los departamentos de La Guajira y de Arauca.

En estudios previos se insiste en el consolidado interés venezolano por lograr el control completo y permanente de la península de La Guajira, teniendo en cuenta sus grandes recursos en carbón, gas natural y sal. Además, el control de La Guajira le permitiría a Venezuela un acceso irrestricto al Golfo de Coquibacoa, aún en litigio con Colombia.

No obstante, la importancia petrolera de los Llanos Orientales colombianos, que se extiende en Venezuela en la unidad petrolera llamada «Cuenca Barinas Apure», es también significativa.

Precisamente dicha cuenca tiene un número de 350 pozos activos y una capacidad de producción estimada en 166 millones de Barriles ${ }^{45}$, por lo que buscar su proyección en territorio colombiano resulta de importancia estratégica para el vecino país.

Por otro lado, la industria agropecuaria colombiana, presente en los Llanos Orientales, representa un complemento significativo a un sector deficitario venezolano.

Ante este panorama, es posible afirmar que le economía decadente de Venezuela puede implicar la búsqueda de las soluciones a sus problemas estructurales por la vía de la consolidación de amenazas hacia Colombia y, en particular, en sectores estratégicos como son Arauca y La Guajira.

\subsection{Arauca, talón de Aquiles colombiano, escenario perfecto para la invasión extranjera. Venezuela, principal amenaza}

De manera particular es Arauca objeto de atención del presente artículo, por ser un lugar estratégico que representa un escenario de intervención e influencia por parte de la Revolución Bolivariana, en tanto que son territorios en los cuales activamente se vincula a la población y a las autoridades con hechos o acontecimientos con los cuales se demarcan asunciones para determinar la potencialidad de las amenazas a la seguridad colombiana, a la vez que provee capacidades de acceso a recursos naturales energéticos, hídricos y en general medios que sirven de soporte para la financiación de la Revolución Bolivariana ${ }^{46}$.

${ }^{45}$ PDVSA. Venezuela (en línea). Búsqueda realizada el 29 de mayo de 2010. Desde: < $\underline{\text { http:// }}$ www.mipunto.com/venezuelavirtual/mapas/mapa hidrocarburos.html $>$.

46 Dentro de los cuales se incluyen los canales de transporte, principalmente fluvial y terrestre, para el paso de los medios comerciables que brindan sustento económico al proyecto venezolano, tales como los provenientes del narcotráfico. 
A la luz del empleo estratégico de los medios masivos de comunicación, ligado al enfoque educativo de adhesión anti-institucional en contra del Estado colombiano a favor de los grupos armados, se presuponen las amenazas cuyo desarrollo tiene lugar debido a que la población de niños, jóvenes y adultos en proceso de alfabetización, en su mayoría cruzan las frontera hacia Venezuela para recibir los contenidos educativos afianzados en hechos como la asistencia recibida en jornadas de salud (principalmente de vacunación, con médicos extranjeros, asociados a las misiones de la Revolución) y recrean así un imaginario en el cual los grupos armados ilegales les brindan seguridad y luchan por sus intereses, de la mano con el régimen venezolano que materializa la atención a sus necesidades básicas. Lo cual supone el cuestionamiento referido a: ¿Qué lugar ocupa en dicho imaginario el Estado colombiano? Lo cual se complejiza cuando al preguntar a un niño araucano de 12 años: ¿Cuál es el himno nacional de su país? Se dispone a entonar el venezolano.

Del mismo modo, se configura un contexto de administración pública empañado por su inefectividad, dado que en tal sociedad araucana algunos de los gobernantes de hoy han sido educados en un entorno de oposición y aislamiento colombiano y han sido cooptados por Venezuela y los grupos armados ilegales ${ }^{47}$. De modo tal que Arauca se configura como un contexto de corrupción y desatención estatal y social desde el centro de Colombia, con nexos generacionales y con grupos y prácticas ilegales que conducen a que la seguridad (desde una perspectiva integral) sea una función a cargo de actores distintos al Estado, vinculados al país vecino y al ELN. De este modo prevalecen configuraciones en torno al impacto de las operaciones militares que, en procura del restablecimiento del orden democrático y la seguridad, enfrentan el riesgo de distorsionar el imaginario y afectar a quienes son objeto de afecto $y$, por tanto, apoyo de la población. Mientras llega el pie de fuerza se ataca a los seres queridos y a quienes han trabajado por dotar de medios y solución a los conflictos de la sociedad araucana, con la consecuente ruptura en la cooperación civil-militar que es dada a los grupos armados ilegales, dejando en vulnerabilidad a la soberanía estatal y, como consecuencia de esto, a la integridad territorial.

47 En Arauca existen adultos mayores que en su juventud fueron miembros de grupos armados ilegales, cuya familia, en especial sus hijos, engrosa hoy las filas de la guerrilla y, por tanto, mantienen como herencia su vínculo al grupo ilegal. A la vez, existen casos particulares en los cuales una mujer joven (hija de un ex miliciano) en condición de embarazo, se mantiene en ejercicio hasta que le sea físicamente posible y una vez da a luz entrega su (s) hijo (s) a la crianza de los abuelos para reintegrarse a su labor en el combate. El abuelo, quien se cuenta como un ex guerrillero, expone que los primeros años de sus nietos son orientados para que una vez crezca, mantenga la tradición y se vincule a la función social que le corresponde: ser miembro activo de la organización ilegal. Cadena de suministro de combatientes que desborda los límites del reclutamiento forzado y lleva a los niños a la guerra o al ejercicio político, con tendencia clara de rechazo al modelo de gobierno central. 


\section{CONCLUSIÓN}

Es posible afirmar que existen tensiones estructurales que determinan las relaciones hemisféricas andinas y, en especial, la dinámica de las relaciones bilaterales entre Colombia y Venezuela. Estas tensiones se construyen, a nivel sistémico, desde la caracterización sociopolítica y económica del sistema venezolano, donde se encuentran huellas de la gestación de amenazas regionales y particularmente dirigidas a la seguridad nacional de Colombia.

El punto de inflexión es el tipo material y la ruta de consolidación de esta amenaza para Colombia. Las dudas se concentran en dos teatros de operaciones muy bien definidos, La Guajira o Arauca, cada uno con gran importancia a nivel de recursos económicos y capital político y social.

El análisis detallado, desde el punto de vista estratégico militar, será el centro de la segunda parte de la presente investigación.

\section{BIBLIOGRAFÍA}

- $\quad$ ADENEY, Bernard. (1988). Just War, Political Realism, and Faith, New Jersey: The Scarecrow Press, p. 146.

- CARDONA D, TOKATLIAN J.G. (1991) Los desafíos de la política internacional colombiana en los noventa. En: Revista Universidad de los andes. Junio. p.3-10.

- EChavarRíA O. Hernán. (2010). La milicia bolivariana dentro del sistema de defensa nacional de Venezuela. En: Observatorio de Política y Estrategia en América Latina. 20, marzo.

- GONZALES U. E. Las dos etapas de la política exterior Chávez. En: revista de ciencias sociales ICONOS. Ecuador.

- MADUEÑO, L. (2002). 'El populismo quilístico en Venezuela. La satisfacción de los deseos y la mentalidad orgiástica'. En: A. Ramos Jiménez (ed.). La transición Venezolana. Aproximación al fenómeno Chávez, Centro de Investigaciones de Política Comparada - CIPCOM -, Universidad de los Andes, Producciones Karol C.A. Mérida.

- MÉNDEZ, C. OTÁlVORA, E.; CARDOZO, E; JÁCOME, F. (2007). Venezuela en el contexto de la seguridad regional. Instituto Latinoamericano de Ciencias Sociales. Caracas, Venezuela.

- Presidencia de la República (2003) - Ministerio de Defensa Nacional. Política de Defensa y Seguridad Democrática. Colombia.

- SÁNCHEZ, Rubén. (2005) Seguridades en construcción en América Latina, El círculo de Colombia: Brasil, Ecuador, Panamá, Perú y Venezuela. Centro de Estudios Políticos e Internacionales -CEPI -. 
- VARGAS PONCE, José y GARCíA, Pablo Andrés. Problemas fronterizos. Problemas Fronterizos ColomboVenezolanos. Instituto Universitario de Tecnología Venezuela.

- WALTZ. K. N. (1988). Teoría de la Política Internacional. Grupo Editorial Latinoamericano, Colección estudios internacionales. Buenos Aires, Argentina.

\section{Recursos electrónicos:}

- AGENCIA EFE. (2010, 16 de marzo). Venezuela dice que actuará sólo si hay «prueba irrefutable» sobre ETA. Disponible en: el Espectador.

- ARAÚJO. (2007, 20 de mayo). «las FARC admiran a Chávez». Disponible en: BBC MUNDO. $<$ http://74.125.45.132/search?q=cache:N82GITsUzNoJ:news.bbc.co.uk/hi/spanish/latin_america/ newsid $6472000 / 6472915 . \mathrm{stm}+$ FARc + se + identifican + con + chavez\&cd $=8 \& h l=e s \& c t=c \operatorname{lnk} \& g \mid=c 0>$

- CANCILLERÍA. (2009, 9 de diciembre). Apoyo de Coordinadora Continental Bolivariana a FARC es afrenta a la democracia. El Tiempo. Disponible en: <http://www.eltiempo.com/archivo/documento/CMS$6772547>$.

- CARLSON, Chris. Venezuela and Iran Increase Economic Integration. Disponible en: < $\underline{\text { http:// }}$ venezuelanalysis.com/news/2480>.

- CARLSON, Chris. (2007, 23 de octubre). Russian President Praises Investment Opportunities in Venezuela. Disponible en: < http://venezuelanalysis.com/news/2755 >.

- El tiempo. (2008,14 de enero). «Con beligerancia, las FARC ttendrían que dejar de secuestrar»: Hugo Chávez. Disponible en: <http://www.eltiempo.com/archivo/documento/CMS-3919177>.

- CUERVO, Jorge Iván. (2008, 21 de enero). Precisiones sobre la beligerancia. Disponible en: El espectador.

- Enciclopedia y biblioteca virtual de economía, Disponible en: < $\underline{\text { http: } / / 74.125 .45 .132 / \text { search?q=cache: }}$ JzckQwmK690J:www.eumed.net/flechas/racioinstitucion.htm + institucion + reglas + de +juego\&cd=

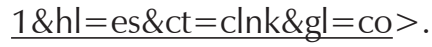

- Declaración de las Naciones Unidas sobre el delito y la seguridad pública. Aprobada el 28 de enero de 1997. Disponible en: < http://www.unodc.org/pdf/event_2006-03-20/RES-51-60\%20S.pdf > .

- FEBLES, Rafael. Fundamentos teóricos de la Revolución Bolivariana. Disponible en: < $\underline{\text { http:// }}$ www.aporrea.org/actualidad/a5505.html>

- GRILlO, Andrés. (2000, 31 de julio). Internacional Bolivariana. Disponible en: Semana. Bogotá.

- GuARíN, Rafael. (2008, 22 de enero). El desnudo de la alianza Chávez-FARC. Disponible en: $<$ http://www.semana.com/wf_InfoArticulo.aspx?ldArt=108978>

- http:www.mindefensa.gov.co/.../Esp_Acuerdo_cooperacion_con_EEUU.pdf 
- Venezuela tuya. Com. La Junta de Gobierno y el pacto de Punto Fijo. Disponible en: http:// www.venezuelatuya.com/historia/democracia.htm

- Gobierno Bolivariano de Venezuela. Ministerio del Poder Popular para Ciencia, Tecnología e Industrias Intermedias. La Estructura Económica de Venezuela desde 1958 hasta la actualidad. Disponible en: < http:/ /www.rena.edu.ve/cuartaEtapa/historia/tema17.html>

- Análitica.com. Disponible en: <http://www.analitica.com/vam/1999.02/nacional/01.htm>

- La revolución en Bolivia no la dirige Evo Morales, sino Hugo Chávez. (2008, 1 de junio). Disponible en: Revista Legal LEX. <http://www.revistalex.com/la-revolucion-en-bolivia-no-la-dirige-evo-morales-sinohugo-chavez/.>

- MOLONEY, Anastasia. (2008, 31 de octubre.) Concern Over Venezuela's Russian Arms Purchases Could Be Misplaced. Disponible en: < http://venezuelanalysis.com/analysis/3918>.

- PETROLLINI, D. Realismo Ofensivo y Realismo Defensivo: El debate Intrarrealista. Centro Argentino de Estudios Internacionales. Programa Teoría de las Relaciones Internacionales. Disponible en: <http:// www.caei.com.ar/es/programas/teoria/29.pdf>.

- PICCIONE, Alberto. Personalidad de Hugo Chávez. Blog Topnews international. Disponible en: $<\underline{\text { http://topnewsinternational.blogspot.com/2009/08/la-personalidad-de-hugo-chavez.html > }}$.

- Plan de Desarrollo para la Venezuela del siglo XXI. Líneas Generales del Plan de Desarrollo. Disponible en: <http://www.slideshare.net/mikhel/plan-de-desarrollo-para-la-venezuela-del-siglo-xxl>

- Revolución Bolivariana o Robo-lución bolchevique. (2009, 5 de agosto). Disponible en: $<$ http://www.diariodeamerica.com/front_nota_detalle.php?id_noticia $=5377>$

- Revelan secretos de Raúl Reyes. (2008, 7 de marzo) Disponible en: El Universal. Caracas.

- RODRÍGUEZ, Paulimar. (2008, 24 de septiembre). 23 de enero tendrá una Plaza para Marulanda. Disponible en: El Universal. Caracas.

- SARAH, Wagner. Venezuela: territorio libre de analfabetismo. Artículo digital disponible en: < http:// www.voltairenet.org/article124921.html>

- Uribe: estatua de 'Tirofijo' en Venezuela recuerda que hay que derrotar al terrorismo. (2010, 22 de abril). Disponible en: Revista Semana.

- VALERY, Yolanda. (2009, 26 de noviembre). Irán y Venezuela de la mano. Disponible en: BBC MUNDO <http://www.bbc.co.uk/mundo/america_latina/2009/11/091125_0053_alianza_iran_venezuela_ jg.shtml>.

- Venezuela busca mecanismos diplomáticos para acabar lío con Colombia. (2008, 19 de mayo). Disponible en: El Espectador. Bogotá. 